\title{
ARTICLE
}

Maternal and pediatric nutrition

\section{Vitamin B12 concentrations in milk from Norwegian women during the six first months of lactation}

\author{
Sigrun Henjum $\mathbb{D}^{1} \cdot$ Mari Manger $^{2} \cdot$ Daniela Hampel $^{3,4} \cdot$ Anne Lise Brantsæeter $\mathbb{D}^{5} \cdot$ Setareh Shahab-Ferdows $\mathbb{D}^{3} \cdot$ \\ Nasser E. Bastani ${ }^{6} \cdot$ Tor A. Strand ${ }^{7,8} \cdot$ Helga Refsum $^{6} \cdot$ Lindsay H. Allen ${ }^{3,4}$
}

Received: 7 June 2019 / Revised: 15 January 2020 / Accepted: 17 January 2020 / Published online: 30 January 2020

(c) The Author(s), under exclusive licence to Springer Nature Limited 2020

\begin{abstract}
Background Human milk vitamin B12 (B12) concentrations depend on maternal status and intake; only few data are available in high-income countries.

Objective We assessed human milk B12 concentrations during the first 6 months postpartum in Norwegian women and its association with maternal dietary B12 intake and maternal urinary methylmalonic acid (MMA) concentration.

Methods In this cross-sectional study, 175 mothers, exclusively (80\%) or partially (20\%) breastfeeding, were included. Milk B12 was measured by IMMULITE /IMMULITE ${ }^{\oplus} 1000$ B12 competitive protein binding assay and urinary MMA relative to creatinine (MMA/Cr) by liquid chromatography-tandem-mass spectrometry. Maternal habitual B12 intake and supplement use were estimated using a food frequency questionnaire.

Results Mean human milk B12 concentration was 327 pmol/L (range 140-1089), with 402 pmol/L at 1 month $(n=21)$, $333 \mathrm{pmol} / \mathrm{L}$ at four months $(n=32)$, and $299 \mathrm{pmol} / \mathrm{L}$ at 6 months $(n=21)$. Maternal B12 intake was $5 \mu \mathrm{g} / \mathrm{d}$, $89 \% \mathrm{met}$ the Estimated Average Requirement, and supplement use did not affect milk B12 concentrations. MMA/Cr was low in all women compared with published data. In exclusively breastfeeding women, MMA/Cr (beta (95\% CI) - 42.5 (-82.5, - 2.5) and time since birth $(-4.9(-9.6,-0.3))$ were significant predictors of human milk B12 concentrations. There was no association between total B12 intake and milk B12 concentration or between total B12 intake and MMA/Cr.

Conclusions Maternal B12 status and human milk B12 concentrations are likely sufficient, based on adequate maternal B12 dietary intake combined with low urinary MMA concentrations. Nevertheless, milk B12 concentration fell during 6 months postpartum while maternal B12 status did not change.
\end{abstract}

Sigrun Henjum

shenjum@oslomet.no

1 Department of Nursing and Health Promotion, Faculty of Health Sciences, Oslo Metropolitan University, 0130 Oslo, Norway

2 Children's Hospital Oakland Research Institute, Oakland, CA 94609, USA

3 USDA/ARS Western Human Nutrition Research Center, Davis, CA 95616, USA

4 Department of Nutrition, University of California, Davis, CA 95616, USA

5 Division of Infection Control, Environment and Health, Norwegian Institute of Public Health, 0213 Oslo, Norway

6 Department of Nutrition, Institute of Medical Biosciences, University of Oslo, 0317 Oslo, Norway

7 Department of Research, Innlandet Hospital Trust, 2380 Brumunddal, Norway

8 Centre for International Health, University of Bergen, 5020 Bergen, Norway

\section{Introduction}

Vitamin B12 (B12) is an essential micronutrient for normal growth and cognitive development in infants [1, 2]. Infant B12 status depends on both sufficient transfer in utero and sufficient transfer through breast milk, both of which are strongly affected by maternal status [2-4]. Maternal B12 status is a strong predictor of exclusively breastfed infant B12 status, both at birth and at 6 months postpartum [5]. In high-income countries, B12 deficiency is rare and usually observed only in exclusively breastfed infants of vegetarian mothers [2]. Milk from well-nourished women is lower in B12 (300 (range 150-700 pmol/L)) compared with infant formulas $(800-1200 \mathrm{pmol} / \mathrm{L})$ [2], and breastfed infants have lower B12 status than formula fed infants [2]. Several studies have examined B12 status in newborns and during infancy in populations that are considered B12replete. Most of these studies show that infants have lower 
serum B12 and higher methylmalonic acid (MMA) compared with older children and adults, but did not measure milk B12 [6]. MMA, measured in blood or urine, is an indicator of B12 status [7]. B12 status of Norwegian women is assumed to be adequate because of regular consumption of meat, fish, and dairy products [8]. In a previous study in Norway, exclusively breastfed infants had lower B12 status at 4-6 months of age than infants consuming formula or bovine milk, but human milk B12 concentration was not measured. The authors suggested that this could be related to different reference ranges for B12 status in breastfed infants rather than a sign of B12 deficiency [9]. The current knowledge on vitamin B12 content in human milk in wellnourished populations is scarce. Therefore, the aim of the current study was to assess B12 concentration in human milk samples and estimate B12 intake in Norwegian mothers and infants during the first 6 months of lactation. The infants' age ranged from 0 to 24 weeks, $80 \%$ were exclusively breastfed. A secondary aim was to examine predictors of human milk B12 concentration, including maternal urinary MMA and maternal dietary intake of B12 from food and supplements.

\section{Methods}

\section{Population and study design}

In this cross-sectional study in Norway, lactating women were recruited during a postnatal care visit from October to December 2016, as part of a study on iodine status in lactating women [10]. Five out of 18 Mother and Child Health Centers in Oslo were randomly selected from a list stratified into five areas representing different regions and socioeconomic groups in Oslo. Women who had delivered an infant within the last 6 months and who were fully or partially lactating and who could read and write Norwegian were invited into the study. In total, 254 women fulfilled the inclusion criteria, 193 accepted and 175 (69\%) completed the study. Participation was equally distributed among the Mother and Child Health Centers (65-75\%). The participants responded to a questionnaire on background information, habitual intake of 31 food groups in the last four weeks, and intake of all dietary supplements (described below). Self-reported background information included the women's age, time since birth, previous pregnancies, height and weight at the time of milk sampling, educational level, and smoking habit. Participants were also asked about their country of birth, how long they had lived in Norway, and what language they spoke at home. The women who agreed to participate gave written informed consent. The present study was conducted according to the guidelines in the Declaration of Helsinki and was approved by the Regional
Committee for Medical and Health Research Ethics Norway (2015/1845).

\section{Collection of human milk samples}

Four breast milk samples per woman were obtained by manual expression into labeled $50 \mathrm{~mL}$ polypropylene centrifuge tubes (Sarstedt, Nümbrecht, Germany); two in the morning just after eating breakfast, and two in the afternoon; two with foremilk; and two with hind milk (one with foremilk and one with hind milk on each occasion). Each woman received detailed oral and written information on how and when to collect and how to store the human milk samples. Between sampling, the milk samples were stored refrigerated at $2-4{ }^{\circ} \mathrm{C}$ from the time of collection until transportation to the laboratory. The four milk samples were pooled (equal volume from each sample) and stored at $-80{ }^{\circ} \mathrm{C}$ until analysis.

\section{Collection of urine samples}

A spot nonfasting maternal urine sample was obtained in the morning, shortly after breastfeeding the infant. The sampled urine was collected into a labeled $100 \mathrm{~mL}$ Vacuette ${ }^{\circ}$ Urine beaker (Greiner Bio-One, Kremsmünster, Austria). The urine sample was stored refrigerated from the time of sampling until transportation to the laboratory. In the laboratory, a subsample of urine was withdrawn from the beaker into a $9.5 \mathrm{~mL}$ Vacuette ${ }^{\oplus}$ Urine tube (Greiner BioOne, Kremsmünster, Austria), which was stored at $-80^{\circ} \mathrm{C}$ until analysis.

\section{Biochemical analyses}

B12 in human milk was analyzed at the USDA, ARS Western Human Nutrition Research Center, Davis, USA, by the IMMULITE ${ }^{\circledR}$ IMMULITE $^{\oplus} 1000$ Vitamin B12 solidphase; competitive chemiluminescent enzyme immunoassay (Siemens, Duluth, GA, USA) [11]. Urinary MMA and creatinine concentration were measured by liquid chromatography-tandem mass spectrometry (LC-MS/MS) at the Department of Nutrition, Institute of Basic Medical Sciences, University of Oslo, Norway. LC-MS/MS was performed using a Shimadzu LC-20ADXR Prominence LC system (Kyoto, Japan) coupled to a Sciex QTRAP5500 mass spectrometer with Turbo $\mathrm{V}$ ion source and TurboIonspray probe (Framingham, MA, USA). Separation of the analytes was achieved using a Restek Ultra AQ C18 $(100 \times 4.6 \mathrm{~mm}, 3 \mu \mathrm{m})$ column. The mobile phases were $(\mathrm{A})$ with an aqueous solution of formic acid [0.4\%] and (B) methanol with $0.4 \%$ formic acid at a flow rate of $0.8 \mathrm{~mL} /$ min. The separation was achieved with a linear gradient from $80 \%$ (A) for $1 \mathrm{~min}$ and $20 \%$ (A) from 1 to $3 \mathrm{~min}$ 
followed by a linear gradient back to $80 \%$ (A) over $5 \mathrm{~min}$. The whole run was $5 \mathrm{~min}$ and the injection volume was $15 \mu \mathrm{L}$. Linear calibration curves of the peak area ratios of analytes and internal standards were used for quantification. Coefficient of variation for MMA was $1.7 \%$. One person with an MMA concentration four times higher than the rest of the group was excluded from the analysis.

\section{Dietary intake of B12 from food and supplements}

The habitual food assessment comprised 31 questions about average consumption frequency of major food groups during the last four weeks. The questions about each food item had seven alternative responses; rarely/never, less than weekly, 1-3 times weekly, 4-6 times weekly, 1-2 times daily, 3-4 times daily, and 5 times daily or more. We transformed frequencies into daily amounts using standard portion sizes for women. Daily intakes of energy and nutrients, including B12 content were estimated using the Norwegian Food Composition Table [12] and FoodCalc [13]. Participants were also asked to report the names and habitual frequency (times per week) of all supplements used. They were also asked to report the supplements consumed during the last $24 \mathrm{~h}$. The amount of B12 contributed by supplements (habitual and in the last $24 \mathrm{~h}$ ) was estimated using information listed by the producers. All reported supplements included other vitamins and micronutrients in addition to B12. A typical vitamin supplement in Norway contains no more than $10 \mu \mathrm{g}$ of B12 (median $2.5 \mu \mathrm{g}$, range $1.3-9.0 \mu \mathrm{g}$ ). Notably, two participants that used prescription tablets (TrioBe tablets; Meda AS (Mylan Health Care Norway), Asker, Norway), of a high dose supplement containing B12 $(500 \mu \mathrm{g})$, folic acid and vitamin B6 [14], were excluded from the dataset.

\section{Variable definitions and cutoff values}

The Institute of Medicine defines the Adequate Intake (AI) of B12 for infants $0-6$ months to be $0.4 \mu \mathrm{g} / \mathrm{d}$ [15]. The concentration of human milk B12 necessary for exclusively breastfed infants to attain the daily AI $(0.4 \mu \mathrm{g} / \mathrm{d})$ is estimated to be $310 \mathrm{pmol} / \mathrm{L}$ assuming an average milk volume of $780 \mathrm{~mL} / \mathrm{d}[2,3]$. The milk B12 concentration in wellnourished women is in the range $150-700 \mathrm{pmol} / \mathrm{L}$, with mean $300 \mathrm{pmol} / \mathrm{L}$ [2]. The estimated B12 intake of 0-6 months old fully or partially breastfed infants was calculated using historic data on age-in-months human milk consumption per day in infants [16]. The Recommended Daily Allowance (RDA) for B12 for lactating women is $2.8 \mu \mathrm{g} / \mathrm{d}$ and the EAR is $2.4 \mu \mathrm{g} / \mathrm{d}$ [15]. In the Nordic countries, the RDA for lactating women is $2.6 \mu \mathrm{g} / \mathrm{d}$ [17]. Normal range for MMA/Cr in urine is $0.0-3.6 \mathrm{mmol} / \mathrm{mol}$ creatinine $[18,19]$. The Human Development Index (HDI) is a statistical composite index of life expectancy, education, and per capita income indicators, which is used to rank countries into four tiers of human development [20].

\section{Statistics}

All data processing and analyses were done using IBM SPSS statistics version 24 (IBM Corp., Armonk, NY, USA). Spearman correlations were performed to determine associations between variables. Vitamin B12 concentration in milk was skewed so all analyses were done using log transform data. In the results, we showed not transformed data to make the interpretation easier. Multiple linear regression analyses were used to explore predictors of B12 concentration in human milk as the outcome variable. The exposure variables were maternal age (years), time since birth (weeks), maternal BMI, smoking status, parity, HDI index, vegetarian practice, maternal dietary B12 intake, B12 supplements $(\mu \mathrm{g} / \mathrm{d})$, urine creatinine, and maternal urinary MMA/Cr (expressed as $\mathrm{mmol} / \mathrm{mol}$ creatinine). All covariates that showed associations $(p<0.10)$ in the crude regression analysis were included in the preliminary multiple regression models. Excluded variables were reintroduced and those that were still associated in this model $(p<$ 0.10) were retained in the final model [21]. The graphs depicting the association $(95 \% \mathrm{CI})$ between $\mathrm{B} 12$ in milk and time since birth, B12 in milk and maternal B12 intake, B12 in milk and maternal urinary $\mathrm{MMA} / \mathrm{Cr}$, and maternal urinary MMA/Cr and maternal B12 intake, were generated in GraphPad Prism (version 8.1.1, GraphPad Software, San Diego, CA, USA).

\section{Results}

The mean age of the mothers was 32 years, $65 \%$ were born in Norway ( $>80 \%$ in high HDI countries), and $51 \%$ had more than 4 years of higher education (Table 1). The mean time since birth at recruitment of the mothers was 11 weeks. Eighty percent of the women were exclusively breastfeeding their infant when the study was conducted. Thirty-four percent reported habitual use of dietary supplements containing B12, while $23 \%$ had taken this supplement in the last $24 \mathrm{~h}$. Only $2 \%$ of the women were vegetarians.

Mean dietary intakes of B12 from food and from food and dietary supplements combined were 4.1 and $5.0 \mu \mathrm{g} / \mathrm{d}$, respectively (Table 2). Mean daily energy intake was $1621 \mathrm{kcal} / 6802 \mathrm{~kJ}$. The calculated total B12 intake was significantly higher in supplement users $(6.4 \mu \mathrm{g} / \mathrm{d})$ than in nonsupplements users $(4.3 \mu \mathrm{g} / \mathrm{d})$. Eighty-two percent of the mothers met the RDA of $2.8 \mu \mathrm{g} / \mathrm{d}, 85 \%$ met the Nordic RDA of $2.6 \mu \mathrm{g} / \mathrm{d}$, and $89 \%$ met the EAR of $2.4 \mu \mathrm{g} / \mathrm{d}$. The main dietary sources of B12 for the mothers were 
Table 1 Sample characteristics maternal characteristics in lactating women $(n=172)$.

\begin{tabular}{|c|c|}
\hline Characteristics & Mean \pm SD \\
\hline Age mother, years & $32 \pm 4.2$ \\
\hline Time since birth, weeks & $11 \pm 6.6$ \\
\hline BMI, $\mathrm{kg} / \mathrm{m}^{2}$ a & $25 \pm 4.7$ \\
\hline BMI categories & $n(\%)$ \\
\hline$<25$ & $107(62.2)$ \\
\hline$\geq 25-29.9$ & $47(27.3)$ \\
\hline$\geq 30$ & $18(10.5)$ \\
\hline \multicolumn{2}{|l|}{ Number of children } \\
\hline One child & $104(60.5)$ \\
\hline More than one child & $68(39.5)$ \\
\hline \multicolumn{2}{|l|}{ Lactation } \\
\hline Exclusive breastfeeding & $138(80.2)$ \\
\hline Partial breastfeeding & $34(19.8)$ \\
\hline \multicolumn{2}{|l|}{ Education } \\
\hline$\leq 12$ years (high school) & $32(18.6)$ \\
\hline $1-4$ years higher education & $51(29.6)$ \\
\hline$>4$ years of higher education & $89(51.7)$ \\
\hline \multicolumn{2}{|l|}{ Country of birth } \\
\hline Norway & $110(64.0)$ \\
\hline Other & $62(35.0)$ \\
\hline \multicolumn{2}{|l|}{ HDI birth country ${ }^{\mathrm{b}}$} \\
\hline Very high HDI & $131(76.2)$ \\
\hline High HDI & $13(7.6)$ \\
\hline Medium HDI & $11(6.4)$ \\
\hline Low HDI & $17(9.9)$ \\
\hline \multicolumn{2}{|c|}{ Habitual use of B12 containing supplement } \\
\hline No & $113(65.7)$ \\
\hline Yes & $59(34.3)$ \\
\hline \multicolumn{2}{|c|}{ Took B12 supplement in the last $24 \mathrm{~h}$} \\
\hline No & $133(75.3)$ \\
\hline Yes & $39(22.7)$ \\
\hline \multicolumn{2}{|l|}{ Vegetarian } \\
\hline No & $168(97.7)$ \\
\hline $\mathrm{Yes}^{\mathrm{c}}$ & $4(2.3)$ \\
\hline
\end{tabular}

${ }^{\mathrm{a}}$ Current weight.

${ }^{b} \mathrm{HDI}$ (human development index) is a statistic composite index of life expectancy, education, and per capita income indicators. It is used to rank countries into four tiers of human development from low to high.

${ }^{\mathrm{c}}$ All four were lacto-ovo vegetarians.

milk, yogurt, and cheese, contributing on average $35 \%$ of the B12 intake, followed by fish (27\%), multivitamin supplements (18\%), eggs (14\%), and meat $(6 \%)$. Maternal urinary MMA was $11.3 \mu \mathrm{mol} / \mathrm{L}$ and creatinine concentration was $9.9 \mathrm{mmol} / \mathrm{L}$. No women had elevated urinary MMA/Cr, defined as MMA/Cr above $3.6 \mathrm{mmol} / \mathrm{mol}$.

The mean milk B12 concentration was $327 \mathrm{pmol} / \mathrm{L}$ (range 140-1089 pmol/L) (Table 3), with no significant differences between supplement users and nonsupplement users (mean (SD) 340 (179) pmol/L vs. 320 (169) pmol/L, $p=0.46$ ). According to time since birth, mean milk concentration was $402 \mathrm{pmol} / \mathrm{L}$ at 1 month, $333 \mathrm{pmol} / \mathrm{L}$ at 4 months and $299 \mathrm{pmol} / \mathrm{L}$ at 6 months. Sixty-two percent of the women had a milk B12 concentration $>310 \mathrm{pmol} / \mathrm{L}$, and nine women had $>700 \mathrm{pmol} / \mathrm{L}$. Only one woman had a milk B12 concentration $<150 \mathrm{pmol} / \mathrm{L}$.

In women who were exclusively breastfeeding, there was a negative association between B12 concentration in milk and time since birth (beta $(95 \% \mathrm{CI})-5.0$ ( -9.7 , -0.2 ), $p=0.04$ ) (Fig. 1). We found no association between total maternal B12 intake and B12 concentration in breast milk (beta $(95 \% \mathrm{CI}) 3.8(-7.0,14.6), p=0.49)$ or between total maternal B12 intake and urinary MMA/Cr (beta $(95 \% \mathrm{CI})-0.61(-1.4,0.21), p=0.14)$. There was an inverse association between MMA/Cr in urine and $\mathrm{B} 12$ concentration in milk (beta $(95 \%$ CI) $-41.4(-79.8$, $-2.9), p=0.03$. There was no association between urinary $\mathrm{MMA} / \mathrm{Cr}$ and time since birth, beta $(95 \% \mathrm{CI})-0.0$ $(-0.01,0.23), p=0.24)$.

The mean estimated B12 intake from human milk from nonsupplemented mothers, in exclusively breastfed infants was $0.31 \mu \mathrm{g} / \mathrm{d},(5,95$ percentiles: $0.16,0.67)$ (Table 4$)$. In exclusively breastfeeding women, a multiple linear regression analysis of predictors of human milk B12 concentration showed that maternal urinary MMA/Cr (beta $(95 \% \mathrm{CI}$ ) $-42.5(-82.5,-2.5), p=0.03)$ and time since birth in weeks (beta $(95 \% \mathrm{CI})-4.9(-9.6,-0.3), p=0.04)$ were significant predictors.

\section{Discussion}

Our data adds to the knowledge on breast milk B12 concentrations from well-nourished women during the first 6 months of lactation in high-income countries. The women had adequate B12 intakes and low urinary MMA/Cr, indicative of an adequate B12 status. Breast milk B12 concentrations were within the normal range for well-nourished women and no differences were found between supplement users and nonsupplement users, indicating that supplement use did not affect the milk B12 concentration.

The mean (SD) concentration of B12 in human milk in our study is similar to estimates for 6 weeks postpartum in a previous study in Norway [22] and at 4 months among Danish women [23] (Table 5). However, the milk B12 concentrations were lower in our study than among women from Canada [24] and USA [25], all of whom consumed a supplement containing high amounts of B12 during both pregnancy and lactation, compared with the $35 \%$ consuming supplements with moderate amounts of B12 during lactation in our sample. 
Table 2 Mean (SD) and percentile distribution of B12 dietary intake and MMA urinary concentrations in lactating women in Norway $(n=172)$.
Table 3 Mean (SD) vitamin B12 concentration in human milk from supplement users and nonsupplement users by time since birth in months $(n=170)$.

\begin{tabular}{|c|c|c|c|c|c|c|c|c|}
\hline & \multirow[b]{2}{*}{ Mean } & \multirow[b]{2}{*}{ SD } & \multirow{2}{*}{$\begin{array}{l}\text { n (\%) above } \\
\text { Cutoff }\end{array}$} & \multicolumn{5}{|c|}{ Percentiles } \\
\hline & & & & 5 & 25 & Median & 75 & 95 \\
\hline B12 intake food only, $\mu \mathrm{g} / \mathrm{d}$ & 4.1 & 1.9 & - & 1.5 & 2.7 & 3.8 & 5.1 & 7.6 \\
\hline B12 intake supplements, $\mu \mathrm{g} / \mathrm{d}^{\mathrm{a}}$ & 2.7 & 1.5 & & 1.3 & 2.0 & 2.5 & 2.6 & 9.0 \\
\hline B12 total intake, $\mu \mathrm{g} / \mathrm{d}^{\mathrm{b}, \mathrm{c}}$ & 5.0 & 2.4 & $155(89)$ & 1.6 & 3.4 & 4.9 & 6.2 & 9.3 \\
\hline Urine MMA, $\mu \mathrm{mol} / \mathrm{L}$ & 11.3 & 9.3 & - & 0.9 & 5.4 & 10.2 & 15.5 & 26.0 \\
\hline Urine $\mathrm{MMA} / \mathrm{Cr}, \mathrm{mmol} / \mathrm{mol}^{\mathrm{d}}$ & 1.1 & 0.5 & $0(0)$ & 0.3 & 0.7 & 1.0 & 1.3 & 2.1 \\
\hline
\end{tabular}

${ }^{\mathrm{a}} \mathrm{B} 12$ intake by supplement users only, $n=59$.

${ }^{\mathrm{b}}$ Estimated Average Requirement (EAR) for lactating women $2.4 \mu \mathrm{g} / \mathrm{d}$.

${ }^{c}$ Mean energy intake was $1621 \mathrm{kcal} / 6802 \mathrm{KJ}$.

${ }^{\mathrm{d}}$ Normal range for MMA in urine is $0.0-3.6 \mathrm{mmol} / \mathrm{mol}$ creatinine $(\mathrm{Cr})$ [18], and 3.6 is used as the cutoff.

\begin{tabular}{|c|c|c|c|c|c|c|}
\hline \multirow[b]{2}{*}{$\begin{array}{l}\text { Time since } \\
\text { birth months }\end{array}$} & \multicolumn{2}{|c|}{ Supplement users $(n=59)$} & \multicolumn{2}{|c|}{$\begin{array}{l}\text { Nonsupplement users } \\
(n=111)\end{array}$} & \multicolumn{2}{|c|}{ Total $(n=170)$} \\
\hline & $\begin{array}{l}\text { B12 milk } \\
\mathrm{pmol} / \mathrm{L}\end{array}$ & $\begin{array}{l}\mathrm{MMA} / \mathrm{Cr} \\
\mathrm{mmol} / \mathrm{mol}\end{array}$ & $\begin{array}{l}\text { B12 milk } \\
\mathrm{pmol} / \mathrm{L}\end{array}$ & $\begin{array}{l}\mathrm{MMA} / \mathrm{Cr} \\
\mathrm{mmol} / \mathrm{mol}\end{array}$ & $\begin{array}{l}\text { B12 milk } \\
\mathrm{pmol} / \mathrm{L}\end{array}$ & $\begin{array}{l}\mathrm{MMA} / \mathrm{Cr} \\
\mathrm{mmol} / \mathrm{mol}\end{array}$ \\
\hline $1(n=21)$ & $370(208)$ & $1.25(0.63)$ & $422(251)$ & $0.92(0.28)$ & $402(231)$ & $1.05(0.46)$ \\
\hline $2(n=57)$ & $308(161)$ & $0.95(0.64)$ & 337 (178) & $0.98(0.44)$ & $327(172)$ & $0.97(0.51)$ \\
\hline $3(n=25)$ & $257(76)$ & $1.21(0.52)$ & $272(114)$ & $1.21(0.58)$ & $266(99)$ & $1.21(0.54)$ \\
\hline $4(n=32)$ & $390(211)$ & $0.95(0.30)$ & $275(89)$ & $1.34(0.58)$ & $333(170)$ & $1.16(0.50)$ \\
\hline $5(n=14)$ & $491(313)$ & $0.62(0.22)$ & $338(226)$ & $1.05(0.55)$ & $360(232)$ & $0.99(0.54)$ \\
\hline $6(n=21)$ & $367(122)$ & $0.98(0.41)$ & 279 (107) & $1.04(0.43)$ & $299(78)$ & $1.10(0.41)$ \\
\hline Total & 340 (179) & $1.03(0.52)$ & $320(169)$ & $1.07(0.49)$ & $327(172)$ & $1.11(0.49)$ \\
\hline
\end{tabular}

In Norway, foods are not fortified with B12, and B12 intake depends on the amounts of foods consumed with a naturally content of B12 in a bioavailable form. Traditionally, Norwegians have a high consumption of animal source foods [8], which agrees with the finding in our study. Compared with our data, B12 intakes were higher among women participating in the Norwegian Mother and Child Cohort Study (MoBa) $(8.5 \mu \mathrm{g} / \mathrm{d}$ from diet and supplements and $6.5 \mu \mathrm{g} / \mathrm{d}$ from diet only) [8], possibly because our FFQ only covered 31 foods compared with 250 foods in MoBa. Our FFQ was designed to capture the intakes of major food groups and showed good validity for calculated iodine intake [26]. Nevertheless, we may have missed some B12 food sources and therefore underestimated total B12 intake within food groups, which could explain the lack of association between B12 intake and milk concentration. In studies from low-income countries with a higher prevalence of deficient or marginal B12 status, maternal vitamin B12 intake was associated with human milk B12 concentrations at 1,6 , and 12 months postpartum in Kenya [27] and Guatemala [1, 2, 28].

Notably, no differences were found in milk B12 concentration between supplement users and nonsupplement users. Maternal B12 supplementation in lactation may be too late to restore adequate milk concentrations and infant status [3]. Randomized controlled trials show that providing recommended amounts of B12 in supplements increased adult and infant serum B12, and human milk concentrations of the vitamin, although not by a substantial amount [2]. Our findings indicate that supplement use did not decrease MMA/Cr concentrations, which could be expected if the women had insufficient B12 status.

We found increasing breast milk B12 concentration with decreasing maternal urinary $\mathrm{MMA} / \mathrm{Cr}$, indicating the expected relationship between maternal B12 status and B12 in human milk in these well-nourished women with normal B12 status. No woman had MMA/Cr above the cutoff, indicating that her B12 status was sufficient. In addition, our data show that even in the range of normal values, maternal B12 status-based on urinary MMA/Cr - is associated with milk B12 concentrations.

B12 deficiency does not occur in healthy infants fed milk from mothers with adequate B12 status [15]. The B12 concentration in milk of Brazilian mothers, which was used to set the AI, was $0.3 \mu \mathrm{g} / \mathrm{d}$ and rounded up to $0.4 \mu \mathrm{g} / \mathrm{d}$ [15], which is in agreement with our findings in milk provided to EBF-infants by unsupplemented mothers. There is no agreed-upon cutoff for adequate B12 concentration in human milk; however, Allen et al. have suggested a mean B12 concentration of 300 (range 150-700) pmol/L in wellnourished women [2]. Only one woman in our study had a 

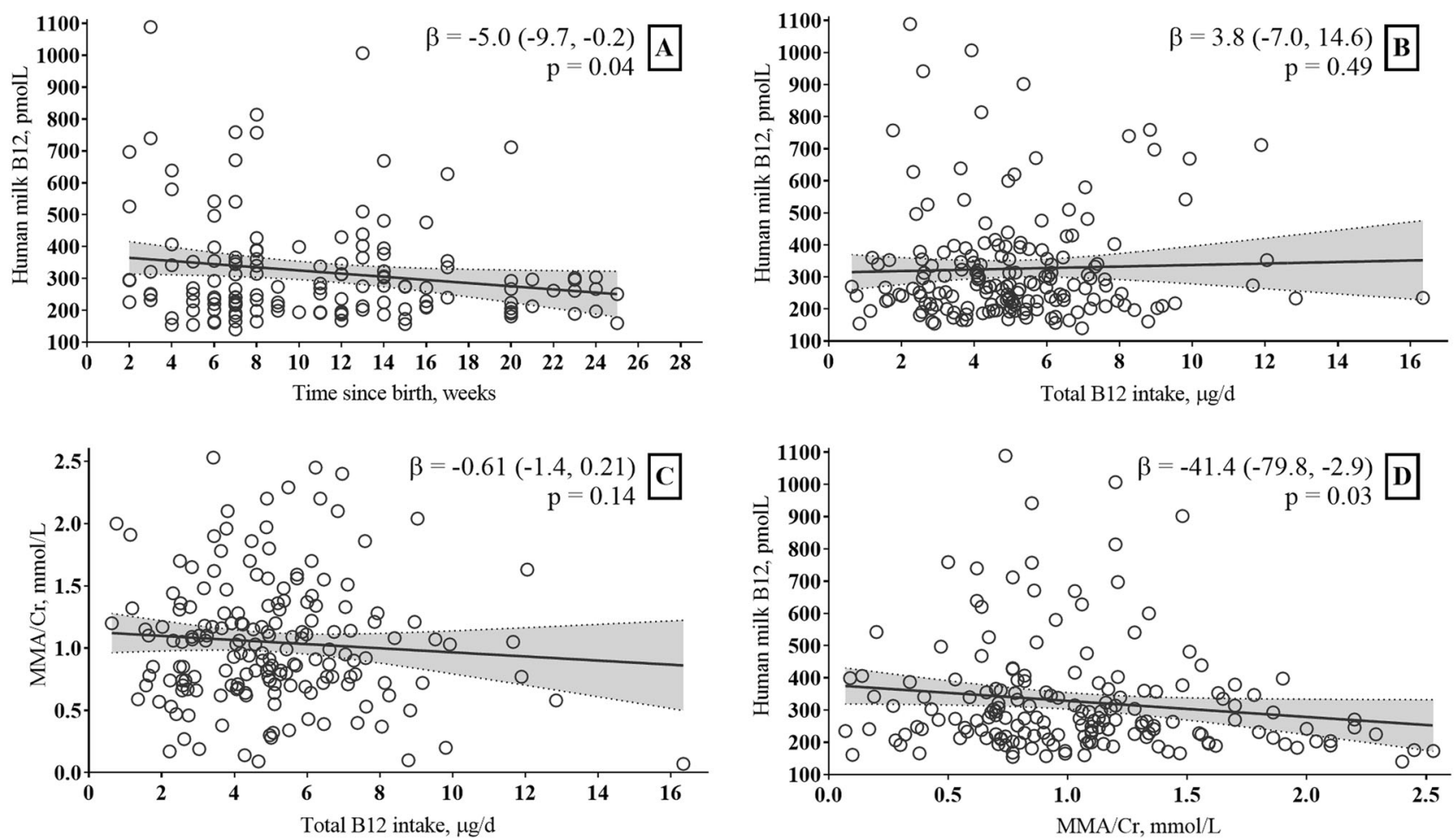

Fig. 1 The graphs show associations among human milk B12, maternal B12 intake and urinary MMA, and infant age. a Association between B12 concentration in human milk and time since birth in weeks. b Association between B12 concentration in human milk and total maternal B12 intake. c Association between B12

Table 4 Estimated vitamin B12 intake by time since birth in exclusively breastfed ${ }^{\mathrm{a}}$ infants of mothers not using vitamin B12 containing dietary supplements $(n=89)$.

\begin{tabular}{llll}
\hline $\begin{array}{l}\text { Time since } \\
\text { birth months }\end{array}$ & $\begin{array}{l}\text { Mean } \\
\text { milk } \\
\text { intakes } \\
\text { L/d }\end{array}$ & $\begin{array}{l}\text { B12 concentration } \\
\text { in human milk } \\
\text { mean (SD) }\end{array}$ & $\begin{array}{l}\text { Estimated B12 } \\
\text { intake from } \\
\text { human milk } \\
\mu \mathrm{g} / \mathrm{d}\end{array}$ \\
\hline $1(n=9)$ & 0.699 & $490(274)$ & $0.47(0.26)$ \\
$2(n=33)$ & 0.731 & $328(160)$ & $0.33(0.16)$ \\
$3(n=13)$ & 0.751 & $249(75)$ & $0.25(0.08)$ \\
$4(n=14)$ & 0.780 & $260(85)$ & $0.28(0.09)$ \\
$5(n=11)$ & 0.796 & $283(129)$ & $0.31(0.14)$ \\
$6(n=9)$ & 0.854 & $205(44)$ & $0.29(0.06)$ \\
Total & 0.780 & $308(159)$ & $0.31(0.15)$ \\
\hline
\end{tabular}

${ }^{a}$ Eighty percent $(n=140)$ of the infants were exclusively breastfeed and $66 \%(n=92)$ of the mothers used no supplements, two women were excluded due to intake of high vitamin B12 containing supplements and one women with high MMA.

${ }^{b}$ Based on milk intakes of exclusively infants from developed countries, WHO, 2002 [16].

milk B12 concentration below $150 \mathrm{pmol} / \mathrm{L}$, thus, we assume that the Norwegian breastfed children met their vitamin B12 requirement from human milk.

concentration in human milk and maternal urinary MMA/Cr. d Association between maternal urinary MMA/Cr and total maternal B12 intake. In 138 exclusively breastfed Norwegian infants. The dotted lines indicate $95 \%$ CI of the association.

Table 5 Comparable studies with human milk B12 measurements.

\begin{tabular}{llrlll}
\hline & Country & $n$ & $\begin{array}{l}\text { Time } \\
\text { postpartum }\end{array}$ & $\begin{array}{l}\text { Supplement } \\
\text { use (\%) }\end{array}$ & $\begin{array}{l}\text { Milk } \\
\text { B12 } \\
\text { (pmol/L) }\end{array}$ \\
\hline Our study & Norway & 172 & 11 weeks ${ }^{\mathrm{a}}$ & 34 & $327^{\mathrm{a}}$ \\
& & 32 & 4 months & 49 & 333 \\
Varsi [22] & Norway & 83 & 6 weeks & 47 & 313 \\
& & & 4 months & & 291 \\
Greibe [23] & Denmark & 25 & 2 weeks & 79 & 760 \\
& & & 4 months & 67 & 290 \\
& & & 9 months & 50 & 440 \\
Chebaya [24] & Canada & 109 & 8 weeks & $100^{\mathrm{b}}$ & 452 \\
Lildballe [25] & USA & 24 & $4-12$ weeks & $100^{\mathrm{b}}$ & 565 \\
\hline
\end{tabular}

${ }^{a}$ Mean time postpartum of sampling and mean concentration of milk B12 for all time points.

${ }^{\mathrm{b}}$ Supplements used during both pregnancy and lactation.

The strengths of this study are the relatively high number of lactating women, of whom $80 \%$ were exclusively breastfeeding, who provided milk samples and gave detailed information of dietary intake and supplement use. The inclusion of lactating women with infants from 0 to 24 weeks is a strength, given that B12 levels fluctuate throughout lactation. We also used the new and more accurate method for measurement of B12 in human milk [11]. The main limitations of the study include the lack of 
data on maternal and infant B12 status in blood and the fact that we only had one milk sample per woman. Although the milk sample was a pooled sample including two samples prior to feeding and two samples after feeding, the samples were collected within a narrow time frame. The FFQ included a limited number of food questions and the calculated mean energy intake indicates that the FFQ did not capture total food intake. In spite of this, the calculated B12 intake was above the RDI for the majority of the participants. Finally, maternal B12 status depend not only on recent B12 intake, but on their internal B12 store. Participants may have taken B12 containing dietary supplements during pregnancy contributing to higher stores, but we have no information on supplements use during pregnancy.

\section{Conclusion}

Milk B12 concentration and maternal B12 status were assumed to be adequate in these healthy, well-nourished women based on adequate dietary B12 intake and low concentrations of maternal urinary MMA/Cr. The decline of milk B12 concentrations over the course of lactation appears to be independent of maternal status in well-nourished populations. The milk B12 concentrations reported here augment the sparse data available for estimating infant and maternal requirements for the vitamin. More research is needed to gain a better understanding of maternal B12 transfer into milk and effects of milk B12 on infant status.

Funding Funded by Oslo Metropolitan University.

Author contributions SH, TAS, ALB, and LA designed the study. SH performed the statistical analysis, DH made Fig. 1 and MM made Table 5 and wrote parts of the discussion. ALB was in charge of the dietary assessment. DH, SS-F and NEB analyzed vitamin B12 in milk and MMA in urine. LHA and HR provided detailed feedback on the paper. All authors read and approved the final paper.

\section{Compliance with ethical standards}

Conflict of interest The authors declare that they have no conflict of interest.

Publisher's note Springer Nature remains neutral with regard to jurisdictional claims in published maps and institutional affiliations.

\section{References}

1. Dror DK, Allen LH. Overview of nutrients in human milk. Adv Nutr. 2018;9:278S-94S.

2. Allen LH, Miller JW, de Groot L, Rosenberg IH, Smith AD, Refsum $\mathrm{H}$, et al. Biomarkers of nutrition for development (BOND): vitamin B-12 review. J Nutr. 2018;148:1995s-2027s.
3. Allen LH. B vitamins in breast milk: relative importance of maternal status and intake, and effects on infant status and function. Adv Nutr. 2012;3:362-9.

4. Molloy AM, Kirke PN, Brody LC, Scott JM, Mills JL. Effects of folate and vitamin B12 deficiencies during pregnancy on fetal, infant, and child development. Food Nutr Bull. 2008;29:101-11.

5. Hay G, Clausen T, Whitelaw A, Trygg K, Johnston C, Henriksen $\mathrm{T}$, et al. Maternal folate and cobalamin status predicts vitamin status in newborns and 6-month-old infants. J Nutr. 2010;140:557-64.

6. Monsen AL, Refsum H, Markestad T, Ueland PM. Cobalamin status and its biochemical markers methylmalonic acid and homocysteine in different age groups from 4 days to 19 years. Clin Chem. 2003;49:2067-75.

7. Sun AL, Ni YH, Li XB, Zhuang XH, Liu YT, Liu XH, et al. Urinary methylmalonic acid as an indicator of early vitamin B12 deficiency and its role in polyneuropathy in type 2 diabetes. $\mathbf{J}$ Diabetes Res. 2014;2014:921616. https://doi.org/10.1155/2014/ 921616.

8. Haugen M, Brantsaeter AL, Alexander J, Meltzer HM. Dietary supplements contribute substantially to the total nutrient intake in pregnant Norwegian women. Ann Nutr Metab. 2008;52:272-80.

9. Hay G, Johnston C, Whitelaw A, Trygg K, Refsum H. Folate and cobalamin status in relation to breastfeeding and weaning in healthy infants. Am J Clin Nutr. 2008;88:105-14.

10. Henjum S, Lilleengen AM, Aakre I, Dudareva A, Gjengedal ELF, Meltzer HM, et al. Suboptimal iodine concentration in breastmilk and inadequate iodine intake among lactating women in Norway. Nutrients. 2017;9:643.

11. Hampel D, Shahab-Ferdows S, Domek JM, Siddiqua T, Raqib R, Allen LH. Competitive chemiluminescent enzyme immunoassay for vitamin B12 analysis in human milk. Food Chem. 2014;153:60-5.

12. The Norwegian Food Composition Table. The Norwegian Directorate of Health and University of Oslo. 2016. http://www. matvaretabellen.no/?language=en. Accessed 26 Apr 2017.

13. FoodCalc. Data Program from the Project "Diet, Cancer and Health" at the Danish Cancer Society. 2005. http://www.ibt.ku.dk/ jesper/foodcalc.

14. TrioBe tablet. Läkemedelsverket [Swedish medical products agency]. TrioBe tablett product information in English. https:// docetp.mpa.se/LMF/TrioBe\%20tablet\%20ENG\%20PL_ 09001be680240cc7.pdf. Accessed 11 May 2019.

15. Institute of Medicine. Dietary reference intakes for thiamin, riboflavin, niacin, vitamin B6, Folate, Vitamin B12, Pantothenic Acid, Biotin, and Choline. Washington, D.C: National Academy Press; 1998.

16. Butte NF, Lopez-Alarcon MG, Garza C. Nutrient adequacy of exclusive breastfeeding for the term infant during the first six months of life. 2002. https://www.who.int/nutrition/publications/ infantfeeding/9241562110/en/.

17. Nordic Council of Ministers. Nordic Nutrition Recommendations 2012 Integrating nutrition and physical activity. 5th edition. 2014. http://norden.diva-portal.org/smash/get/diva2:704251/FUL LTEXT01.pdf.

18. Erdogan E, Nelson GJ, Rockwood AL, Frank EL. Evaluation of reference intervals for methylmalonic acid in plasma/serum and urine. Clin Chim Acta. 2010;411:1827-9.

19. Rasmussen K. Studies on methylmalonic acid in humans. I. Concentrations in serum and urinary excretion in normal subjects after feeding and during fasting, and after loading with protein, fat, sugar, isoleucine, and valine. Clin Chem. 1989;35:2271-6.

20. United Nations Development Programme. Human Development Index (HDI): United Nations Development Programme. http://hdr. undp.org/en/content/human-development-index-hdi. Accessed 15 May 2019. 
21. Hosmer D, Lemeshow W. S. Applied Logistic Regression. New York: John Wiley \& Sons; 2000.

22. Varsi K, Ueland PM, Torsvik IK, Bjorke-Monsen AL. Maternal serum cobalamin at 18 weeks of pregnancy predicts infant cobalamin status at 6 months-a prospective, observational study. J Nutr. 2018;148:738-45.

23. Greibe E, Lildballe DL, Streym S, Vestergaard P, Rejnmark L, Mosekilde L, et al. Cobalamin and haptocorrin in human milk and cobalamin-related variables in mother and child: a 9-mo longitudinal study. Am J Clin Nutr. 2013;98:389-95.

24. Chebaya P, Karakochuk CD, March KM, Chen NN, Stamm RA, Kroeun H, et al. Correlations between maternal, breast milk, and infant vitamin B12 concentrations among mother-infant dyads in Vancouver, Canada and Prey Veng, Cambodia: An Exploratory Analysis. Nutrients. 2017;9:E270.
25. Lildballe DL, Hardlei TF, Allen LH, Nexo E. High concentrations of haptocorrin interfere with routine measurement of cobalamins in human serum and milk. A problem and its solution. Clin Chem Lab Med. 2009;47:182-7.

26. Henjum S, Brantsaeter AL, Kurniasari A, Dahl L, Aadland EK, Gjengedal ELF, et al. Suboptimal iodine status and low iodine knowledge in young Norwegian women. Nutrients. 2018;10:941.

27. Neumann CG, Oace SM, Chaparro MP, Herman D, Drorbaugh N, Bwibo NO. Low vitamin B12 intake during pregnancy and lactation and low breastmilk vitamin 12 content in rural Kenyan women consuming predominantly maize diets. Food Nutr Bull. 2013;34:151-9.

28. Deegan KL, Jones KM, Zuleta C, Ramirez-Zea M, Lildballe DL, Nexo E, et al. Breast Milk Vitamin B-12 Concentrations in Guatemalan Women Are Correlated with Maternal but Not Infant Vitamin B-12 Status at 12 Months Postpartum. J Nutr. 2012;142:112-6. 